\title{
Spectroscopic investigations of dispersion-shifted fiber with thin active Bi-doped ring and high nonlinear refractive index
}

\begin{abstract}
A. S. Zlenko, U. G. Akhmetshin, V. A. Bogatyrjov, L. I. Bulatov, V. V. Dvoyrin, et al.
\end{abstract}

A. S. Zlenko, U. G. Akhmetshin, V. A. Bogatyrjov, L. I. Bulatov, V. V. Dvoyrin, S. V. Firstov, E. M. Dianov, "Spectroscopic investigations of dispersion-shifted fiber with thin active Bi-doped ring and high nonlinear refractive index," Proc. SPIE 7501, International Conference on Ultrafast and Nonlinear Optics 2009, 75010N (11 November 2009); doi: 10.1117/12.848187 


\title{
Spectroscopic investigations of dispersion-shifted fiber with thin active Bi-doped ring and high nonlinear refractive index.
}

\author{
A.S. Zlenko*, U.G. Akhmetshin, V.A. Bogatyrjov, L.I. Bulatov, \\ V.V. Dvoyrin, S.V. Firstov, E.M. Dianov \\ Fiber Optics Research Center, Russian Academy of Sciences, \\ 38 Vavilov st., 119333 Moscow, Russia
}

\begin{abstract}
A germanium-doped silica-core fiber with an active region in the form of a thin ring of silica doped with bismuth ions was fabricated. Bismuth doping in the ring surrounding the core allows to stabilize bismuth in silica glass, and it does not impose any restrictions on the composition of the core. The bismuth concentration in the ring is less than $0.2 \mathrm{wt} . \%$. The $\mathrm{GeO}_{2}$ concentration in the core is more than $15 \mathrm{~mol} \%$. A high germanium concentration in the core allows to shift the zero dispersion wavelength to $1860 \mathrm{~nm}$ and to obtain a high nonlinear refractive index $\left(\mathrm{n}_{2}\right.$ more than $3,2 * 10^{-20}$ $\left.\mathrm{m}^{2} / \mathrm{W}\right)$. Spectroscopic investigations were carried out in the visible and near infrared $(800-1700 \mathrm{~nm})$ spectral range. Despite the small concentration of bismuth, we observed the absorption and luminescence characteristic bands, confirming the presence of bismuth active centers in silica glass. Upon pumping at $1350 \mathrm{~nm}$ the on/off gain spectrum was measured on a $20-\mathrm{m}$ fiber. The gain was observed throughout investigated range of $1430-1530 \mathrm{~nm}$. The maximal gain of $\sim 9.5 \mathrm{~dB}$ was obtained near $1430 \mathrm{~nm}$. The results of the spectroscopic investigations of the fiber with a thin active Bi-doped ring showed prospects of the creation and application of such fiber type for laser and nonlinear optics.
\end{abstract}

Keywords: spectroscopic investigation, bismuth, fiber, preform fabrication, FCVD, ring doping.

\section{INTRODUCTION}

Recently, lasing in bismuth-doped-silica-core optical fibers in the spectral region of 1140-1550 nm was demonstrated $[1,2,3,4,5]$. The lasing depends on the composition of the core glass. The luminescence spectrum of silica glass, in which bismuth is the only impurity, covers the range 1100-1700 nm [6]. Optical fibers with a similar composition appear to be quite promising for the creation of telecommunication amplifiers. Such amplifiers, being integrated into the existing lines, would extend the traditional spectral range of signal transmission $(\mathrm{C}$ - and L- bands, 1.53-1.625 $\mu \mathrm{m}$ ). In addition, from a scientific point of view, the system "silica glass - bismuth» is rather simple and is of interest for an understanding of the nature of bismuth active center.

The bismuth doping into the fiber core is connected with technological constraints, because bismuth has a strong tendency to evaporation during the tube collapsing process [7,8]. This fact causes, in particular, accidental distortions of the refractive index profile of the fiber preform. Also, because of the evaporation of bismuth, the collapsing process may fail for example owing to the formation of bubbles in the preform core. Therefore, silica doping with bismuth at high temperatures is not easy.

We have partially solved this problem by adding bismuth into silica layers before the collapsing process. Let us call it bismuth-ring doping. In the process of manufacturing the fiber preform by FCVD method (Furnace Chemical Vapor Deposition) [9,10], the temperature of the formation of layers is significantly lower than the temperature of the tube collapsing process. Hence, it is possible to assume that bismuth doping of the layers of the inner cladding will be more predictable than bismuth core doping, and will provide a controllable refractive index profile. In turn, the control of the refractive index profile will make it possible to create active fibers with the specified parameters (chromatic dispersion, mode-field diameter, etc.).

*aszlenko@fo.gpi.ru

International Conference on Ultrafast and Nonlinear Optics 2009, edited by Solomon Saltiel, Alexander Dreischuh, Ivan Christov, Proc. of SPIE Vol. 7501, $75010 \mathrm{~N} \cdot$ ? 2009 SPIE · CCC code: 0277-786X/09/\$18 - doi: 10.1117/12.848187

Proc. of SPIE Vol. 750175010 N-1 
In papers $[11,12]$ it is theoretically shown that the Yb-ring-doping in some cases can be used to improve the parameters of corresponding cladding-pumped fiber laser and to reduce the quenching. We decided to explore the possibility of applying this approach to the bismuth-doped fiber manufacture. This paper is devoted to spectroscopic research of a Bi-ring-doped fiber. Absorption, luminescence, and on/off gain measurements, as well as theoretical calculations of the chromatic dispersion and nonlinear refractive index of the Bi-ring-doped fiber are presented.

\section{PREFORM AND FIBER FABRICATION}

The preform was made by the FCVD-method $[9,10]$. A Heraeus Suprasil-F300 tube was used as the substrate tube. The inner surface of the tube before the beginning of layers deposition was polished by $\mathrm{CF}_{4}$ gas. Bismuth doping was carried out via porous silica layer infiltration [13] with BiOCl solution. Impregnated layer was dried and fused into a glassy layer, forming a ring area of silica glass doped with bismuth only. Next, the core was formed through the deposition of layers of silica glass doped with germanium. At the end of process the tube was collapsed in an atmosphere of germanium tetrachloride and oxygen.

Refractive index profile of the fiber preform obtained is shown in Fig. 1. In cross-section of fiber drawn from this preform the layer doped with bismuth must take the form of a ring, approximately $600 \mathrm{~nm}$ in thickness [14]. The bismuth concentration in the fiber is less than $0.2 \mathrm{wt} . \%$. The $\mathrm{GeO}_{2}$ concentration in the fiber core is larger than 15 mol.\%.

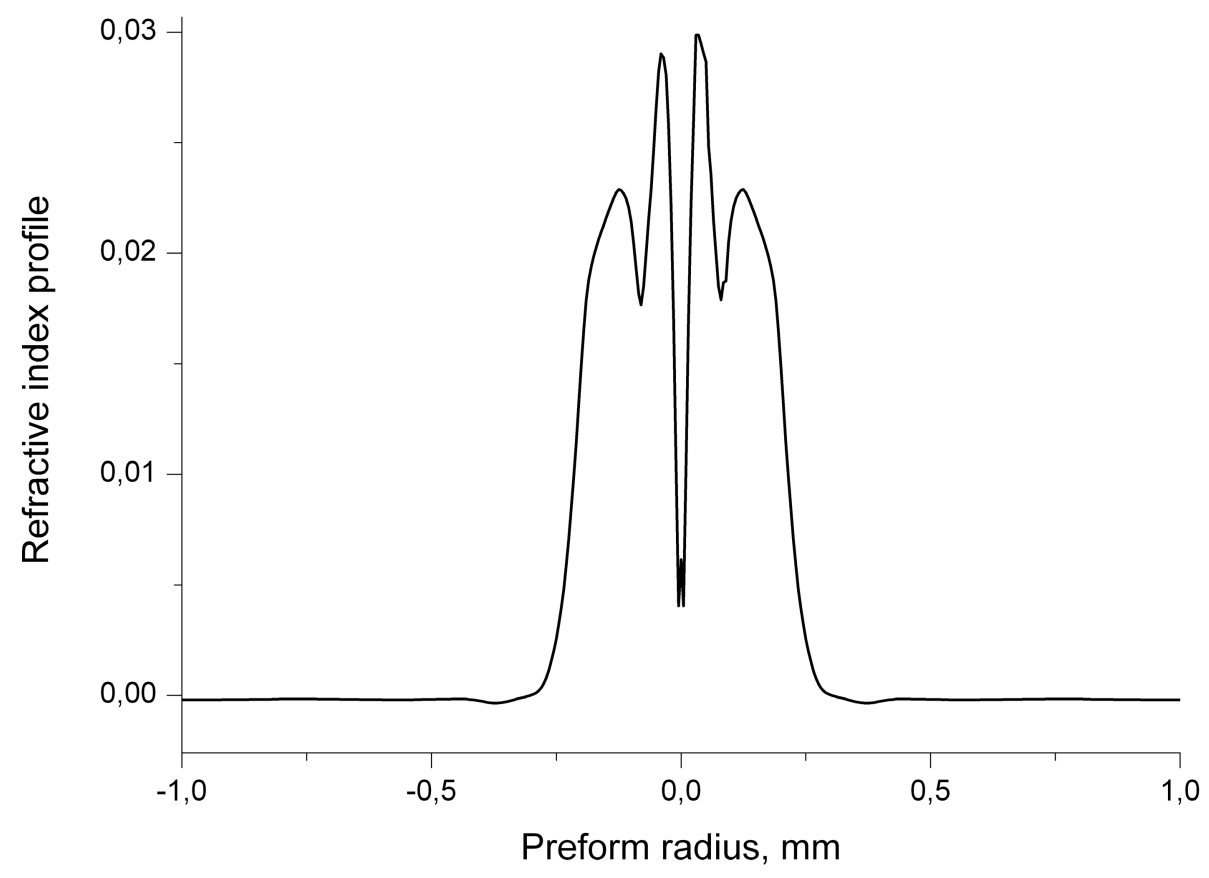

Fig. 1. Refractive index profile of the fiber preform

\section{SPECTROSCOPIC INVESTIGATIONS OF THE BI-RING-DOPED FIBER}

Absorption and luminescence spectra of fiber were measured with the excitation in the fiber core. The absorption spectra were measured by a standard method of comparing the intensities of output radiation at the long and short segments of fiber. The characteristic absorption spectrum of the fiber in the visible region is shown in Fig. 2 and in the near infrared region is shown in Fig. 3. 


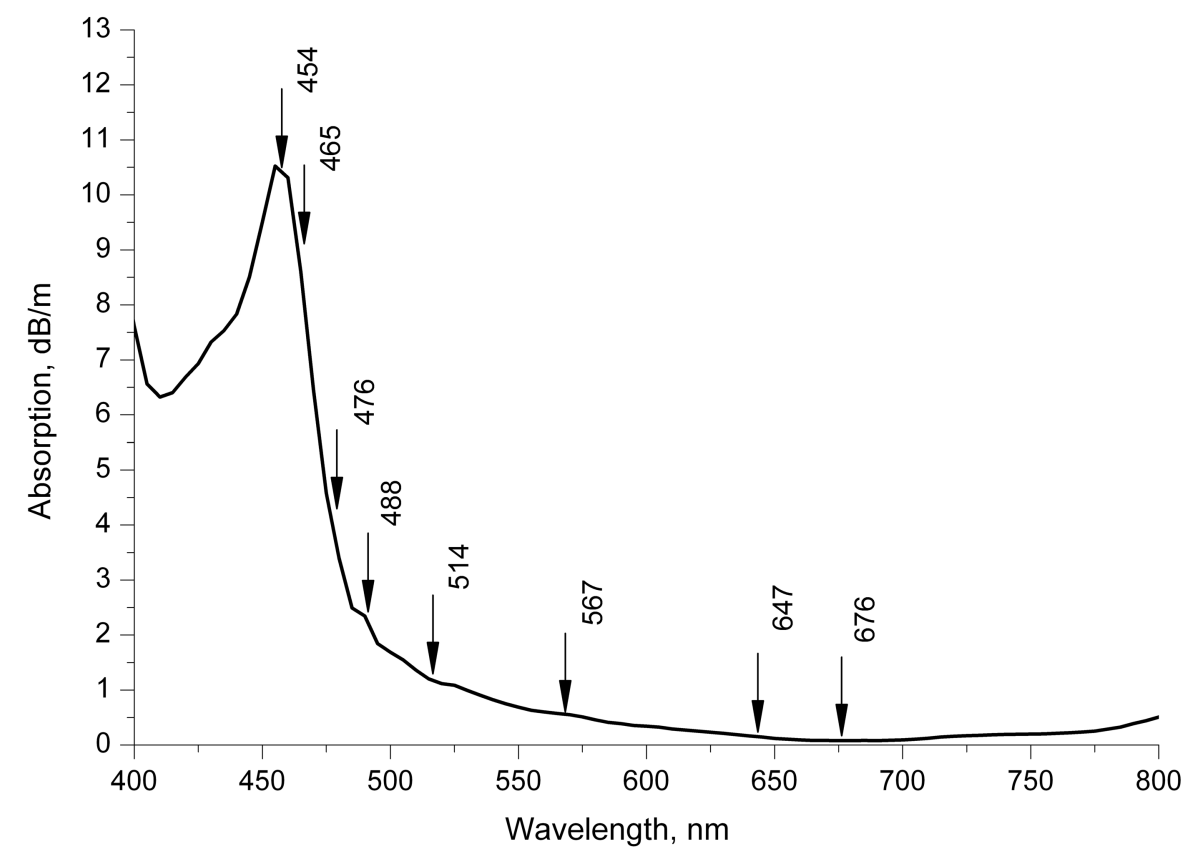

Fig. 2. Absorption spectrum of the fiber in the visible region.

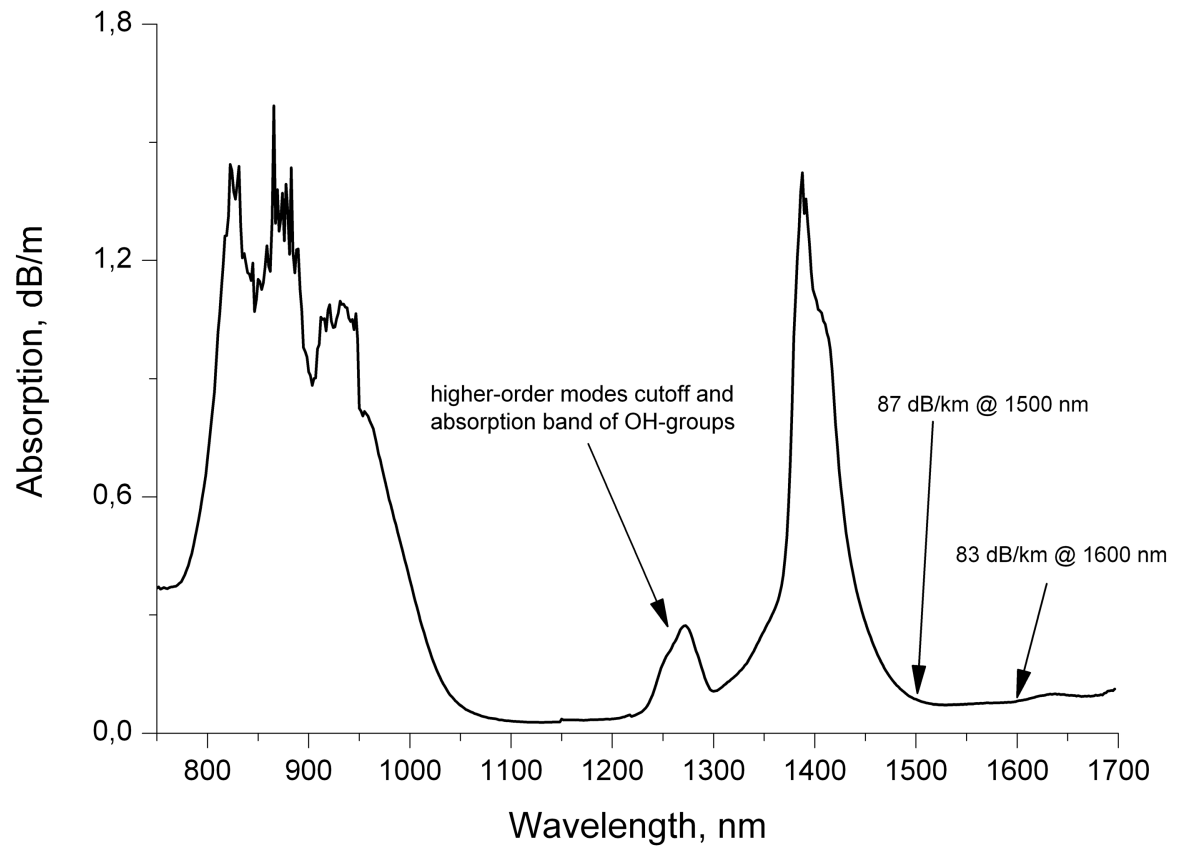

Fig. 3. Absorption spectrum of the fiber in the near infrared region.

Despite the small concentration of bismuth in silica glass, we observed characteristic absorption bands of the $\mathrm{Bi}$ active center. In the visible region there is an intensive absorption band with the maximum on $455 \mathrm{~nm}$, and also less expressed spectral components at $\sim 430$ and $\sim 520 \mathrm{~nm}$. In the spectral region $800-1700 \mathrm{~nm}$ there is four intensive absorption bands at 820, 870, 935 and $1350 \mathrm{~nm}$. The characteristic absorption bands of OH-groups are located near 1240 and $1380 \mathrm{~nm}$, and the latter masks one of the absorption bands of the active center. Also, a higher-order modes cutoff 
$(1230-1300 \mathrm{~nm})$ is visible. The optical loss at $1650 \mathrm{~nm}$ is $0.08 \mathrm{~dB} / \mathrm{m}$, which is not so high for the fiber with such a high concentration of $\mathrm{GeO} 2$ and containing in addition active ions.

Luminescence excitation was carried out using the pump emitting into the input end of the fiber, and the luminescence spectra measurements were fulfilled from the output end of the fiber. The fiber length was $1-10 \mathrm{~cm}$, depending on the spectral range to reduce the distortion of spectra as a result of reabsorption. All luminescence spectra were measured in the spectral region $800-1700 \mathrm{~nm}$. And they have characteristic bands confirming the presence of the bismuth active centers in the silica glass.

The $\mathrm{Kr}+-\mathrm{Ar}+$ laser with a wavelength generation from 454 to $676 \mathrm{~nm}$ was used in the visible range for the luminescence excitation as shown in Fig. 2. Normalized luminescence spectra for excitation wavelengths 454, 465, 476, 488, $514 \mathrm{~nm}$, measured with the same pump power, are presented in Fig. 4. It should be noted that we were unable to measure luminescence spectra upon excitation at 567, 647 and $676 \mathrm{~nm}$ because of low intensity. The luminescence spectrum, which was measured upon excitation in the absorption band at $\sim 450 \mathrm{~nm}$, has the bands with maximums near 830, 960, 1200 and $1400 \mathrm{~nm}$. Luminescence characteristics of bismuth active center are strongly dependent on the excitation wavelength. Therefore changing of excitation wavelength from 454 to $514 \mathrm{~nm}$ leads to significant changes in the luminescence spectrum (Fig. 4). This is showing not only that the luminescence has multicomponent structure, but also that the absorption spectrum has the complex structure in the visible region. Qualitative analysis of the luminescence spectra allows marking out at least 7 components with maximums near 830, 930, 975, 1180, 1270, 1350 and $1430 \mathrm{~nm}$.

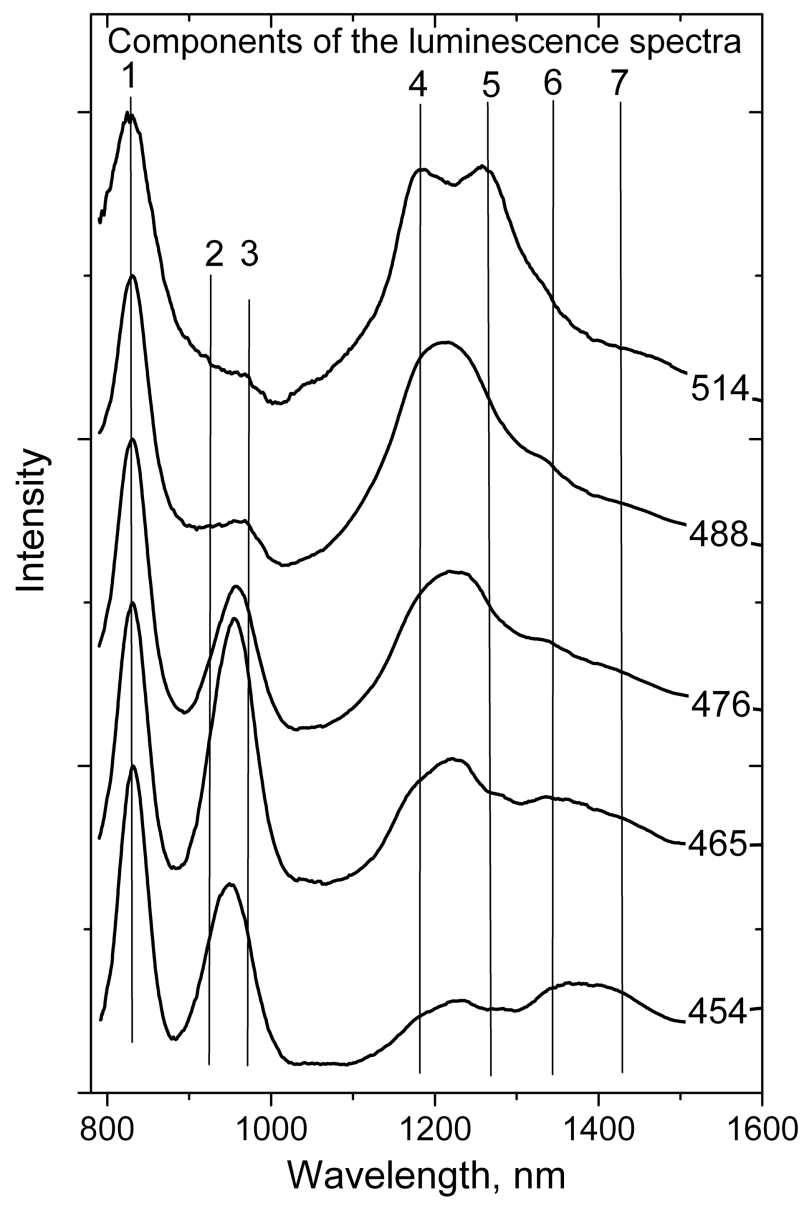

Fig. 4. Normalized luminescence spectra for excitation wavelengths 454, 465, 476, 488, $514 \mathrm{~nm}$, measured with the same pump power.

In the near infrared region pumping at 808 and $1350 \mathrm{~nm}$ was used for the luminescence excitation. Upon excitation at the wavelength of $808 \mathrm{~nm}$ two luminescence bands are observed near 825 and $1400 \mathrm{~nm}$ (Fig. 5). Upon excitation at $1350 \mathrm{~nm}$, a single band with a maximum near $1400 \mathrm{~nm}$ is seen in Fig. 6. 


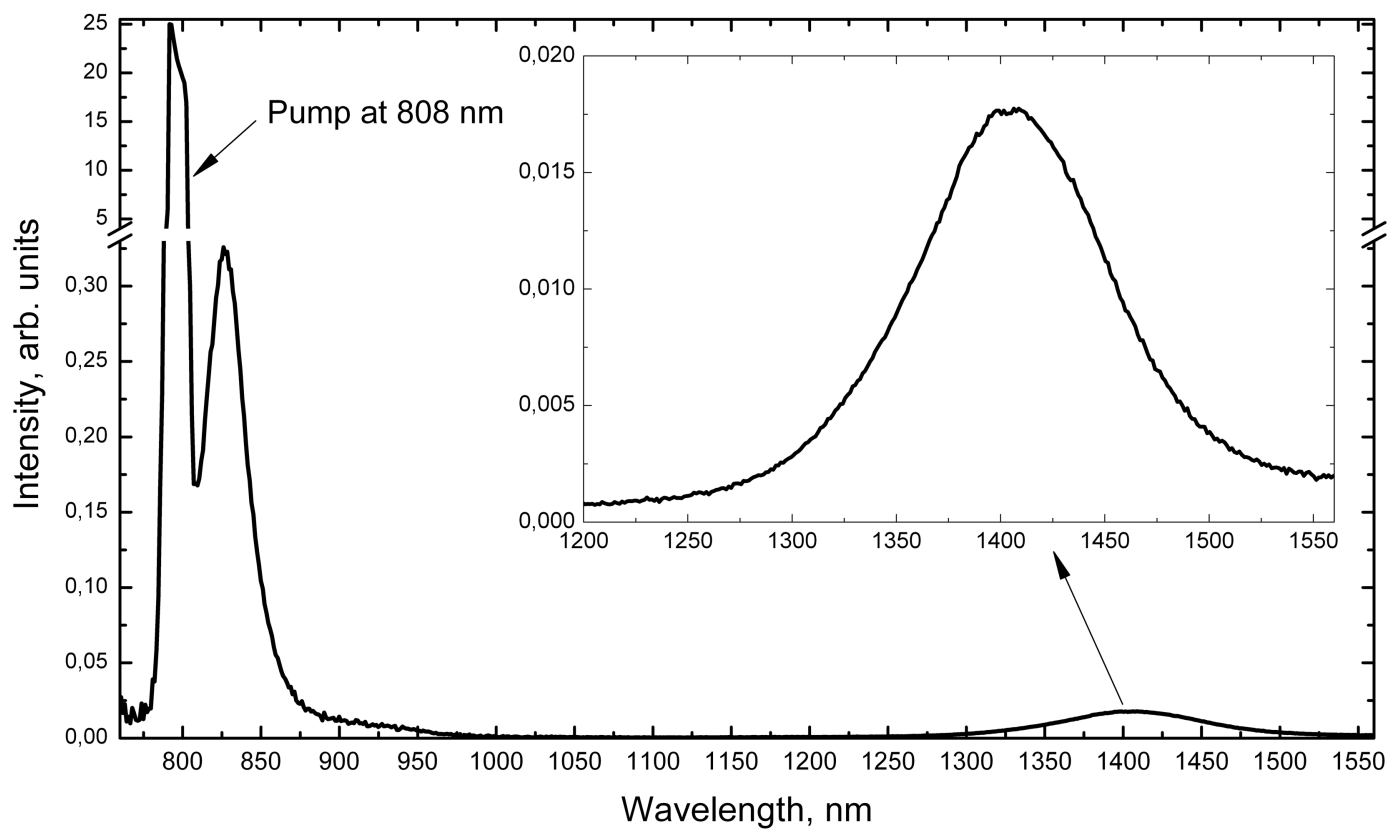

Fig. 5. Luminescence spectrum of the fiber upon excitation at $808 \mathrm{~nm}$.

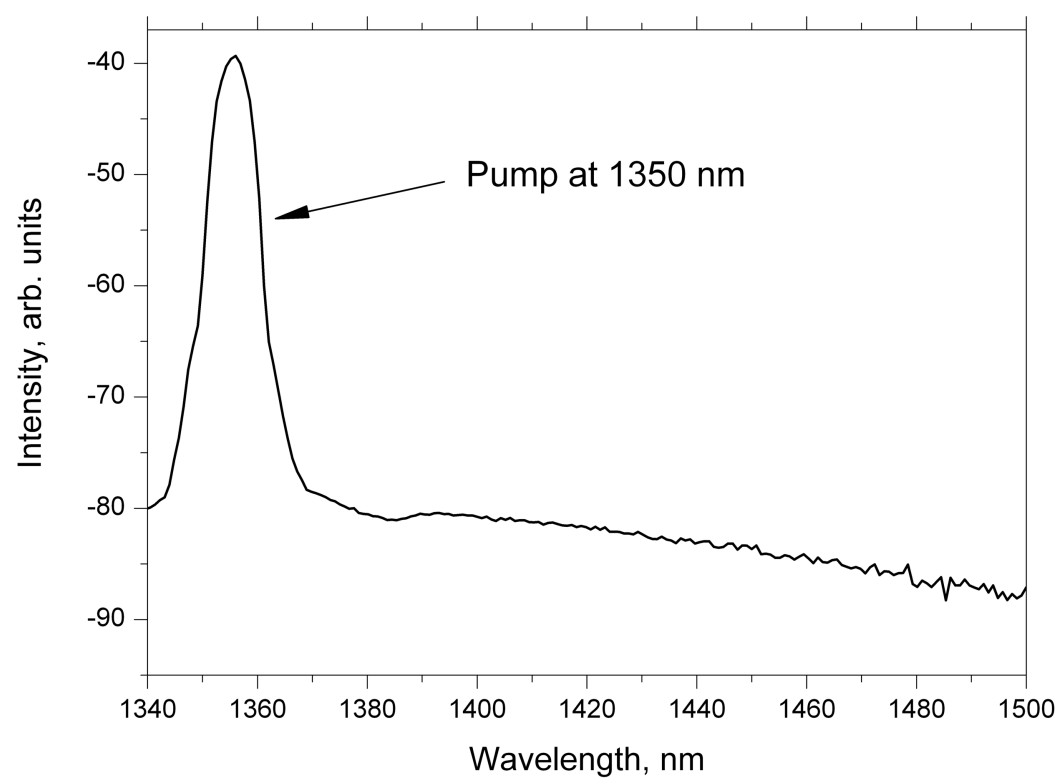

Fig. 6. Luminescence spectrum of the fiber upon excitation at $1350 \mathrm{~nm}$.

It should be emphasized that this paper does not consider the mechanisms of bismuth diffusion to the core and germanium diffusion to the cladding, but note that the luminescence and absorption spectra correlate well with the data obtained in [6] for pure silica glass, doped with bismuth.

When pumping at $1350 \mathrm{~nm}$, the on/off gain spectrum was measured on a $20-\mathrm{m}$ fiber. The gain was observed throughout the investigated range of 1430-1530 nm (Fig. 7). 


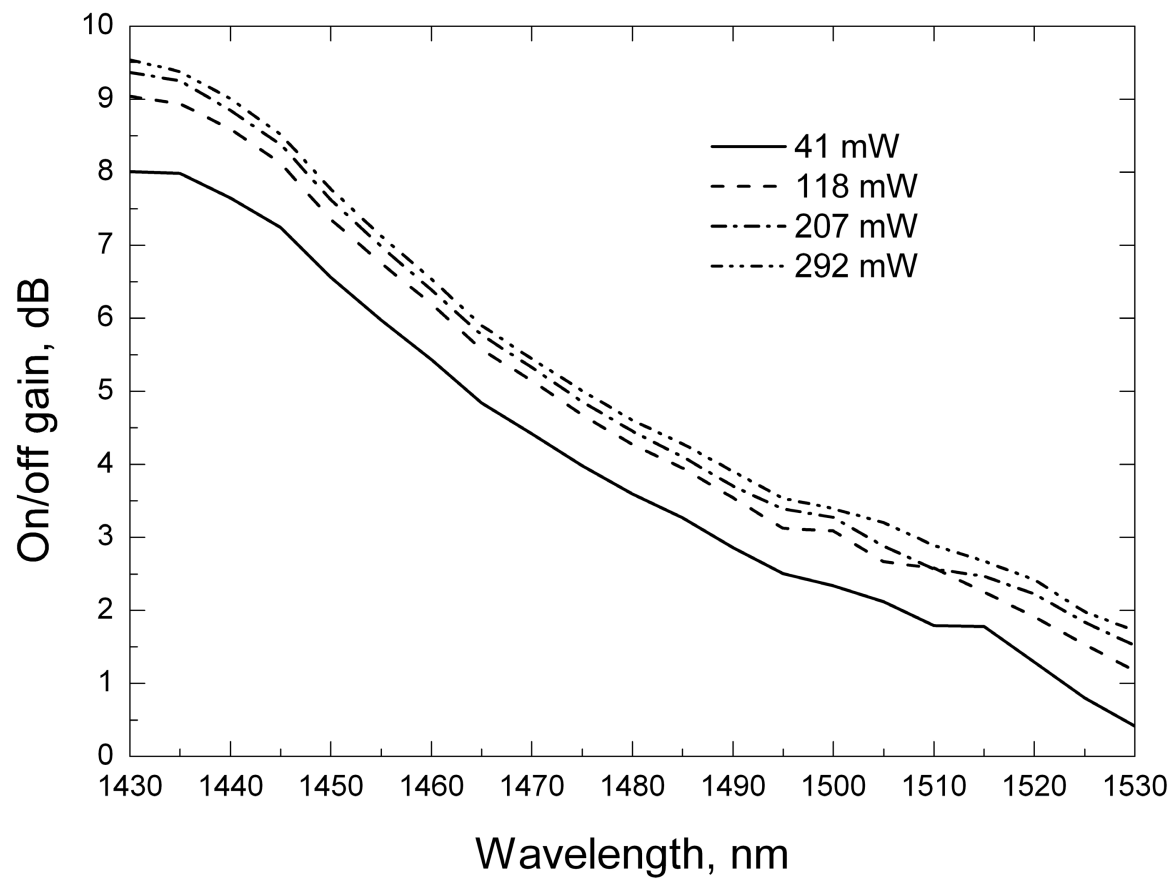

Fig. 7. On/off gain spectrum of the fiber upon $1350 \mathrm{~nm}$ pumping.

The gain was measured at different pump power: from $42 \mathrm{~mW}$ up to $292 \mathrm{~mW}$. The pump power of gain saturation in all the range amounted to $292 \mathrm{~mW}$. The maximal gain of $\sim 9.5 \mathrm{~dB}$ was obtained near $1430 \mathrm{~nm}$. At $1530 \mathrm{~nm}$, the gain remained still visible reaching a value of $2 \mathrm{~dB}$.

\section{THEORETICAL CALCULATIONS OF CHROMATIC DISPERSION AND NONLINEAR REFRACTIVE INDEX OF THE BI-RING-DOPED FIBER}

With the help of numerical solution of equation (1) [15] radial distribution $F(r)$ for refractive index profile in Fig. 1 can be found, and then it is possible to approximately evaluate some optical parameters of the fiber, for example, the mode-field diameter, or the chromatic dispersion [16].

$$
\frac{\partial^{2} F(r)}{\partial r^{2}}+\frac{1}{r} \cdot \frac{\partial F(r)}{\partial r}+\left(\left(\frac{2 \pi}{\lambda}\right)^{2} n(r)^{2}-\beta^{2}-\frac{m^{2}}{r^{2}}\right) F(r)=0
$$

Fig. 8 shows the calculated spectral dependence of chromatic dispersion. One can see that the zero-dispersion wavelength is situated in the region of $1860 \mathrm{~nm}$, and hence, the fiber can be used for dispersion compensation in a wide spectral range. 


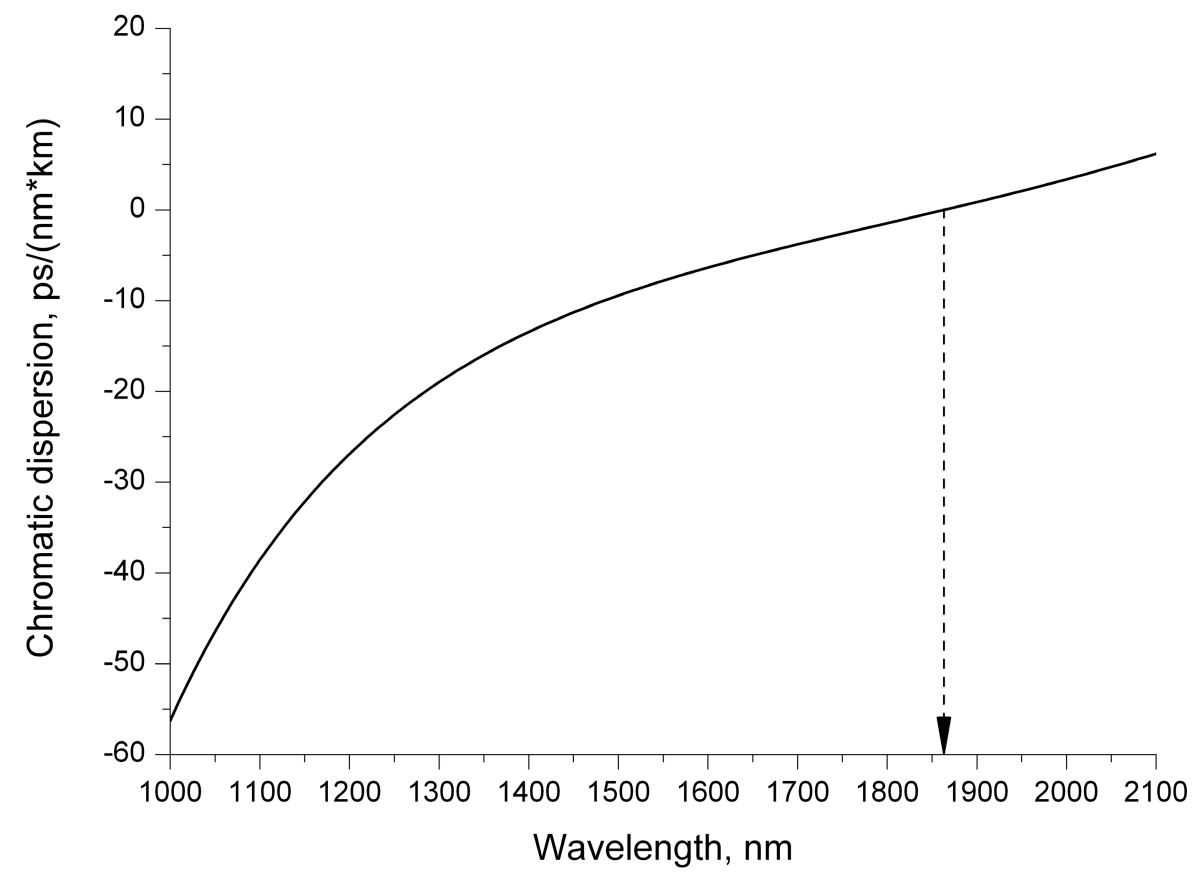

Fig. 8. Chromatic dispersion of the fiber.

The method described in [17] is used for approximate calculation of the nonlinear refractive index of the fiber. To evaluate the effective $\mathrm{n}_{2}$ following formulas are used:

$$
\begin{gathered}
n_{2}[\text { fiber }]=a \eta_{\text {eff }}+n_{2, S i O_{2}} \\
\eta_{\text {eff }}=\frac{\int_{0}^{\infty} \eta(r)|F(r)|^{4} r d r}{\int_{0}^{\infty}|F(r)|^{4} r d r} \\
n_{2}\left[\times 10^{-20} \mathrm{~m}^{2} / \mathrm{W}\right]=0.0552 \eta_{\text {eff }}\left[\mathrm{mol}^{2} \%\right]+2.44
\end{gathered}
$$

Where $n_{2}$ [fiber] is the effective nonlinear refractive index of fiber;

$a$ is a constant, defined as a result of averaging the experimental data: $a=0.0552\left[\times 10^{-20} \mathrm{~m}^{2} /(\mathrm{W} \cdot \mathrm{mol} . \%)\right][17]$;

$\eta_{\text {eff }}[\mathrm{mol} . \%]$ is the effective concentration of $\mathrm{GeO}_{2}$ in molar percentage determined by (3);

$\eta(r)$ is the $\mathrm{GeO}_{2}$ concentration distribution in molar percentage determined by the refractive index profile (Fig. 1) in the assumption of a linear dependence of the index difference on the germanium concentration [18];

$n_{2, \mathrm{SiO}_{2}}$ is $\mathrm{n}_{2}$ of pure $\mathrm{SiO}_{2}$ (the slight dependence of $n_{2, \mathrm{SiO}_{2}}$ on wavelength [19] is ignored), its value is assumed to be $2.44\left[\times 10^{-20} \mathrm{~m}^{2} / \mathrm{W}\right][17]$.

By substituting values of constants expression (2) is converted into expression (4). The calculated spectral dependence of the effective nonlinear refractive index is shown at Fig. 9. 


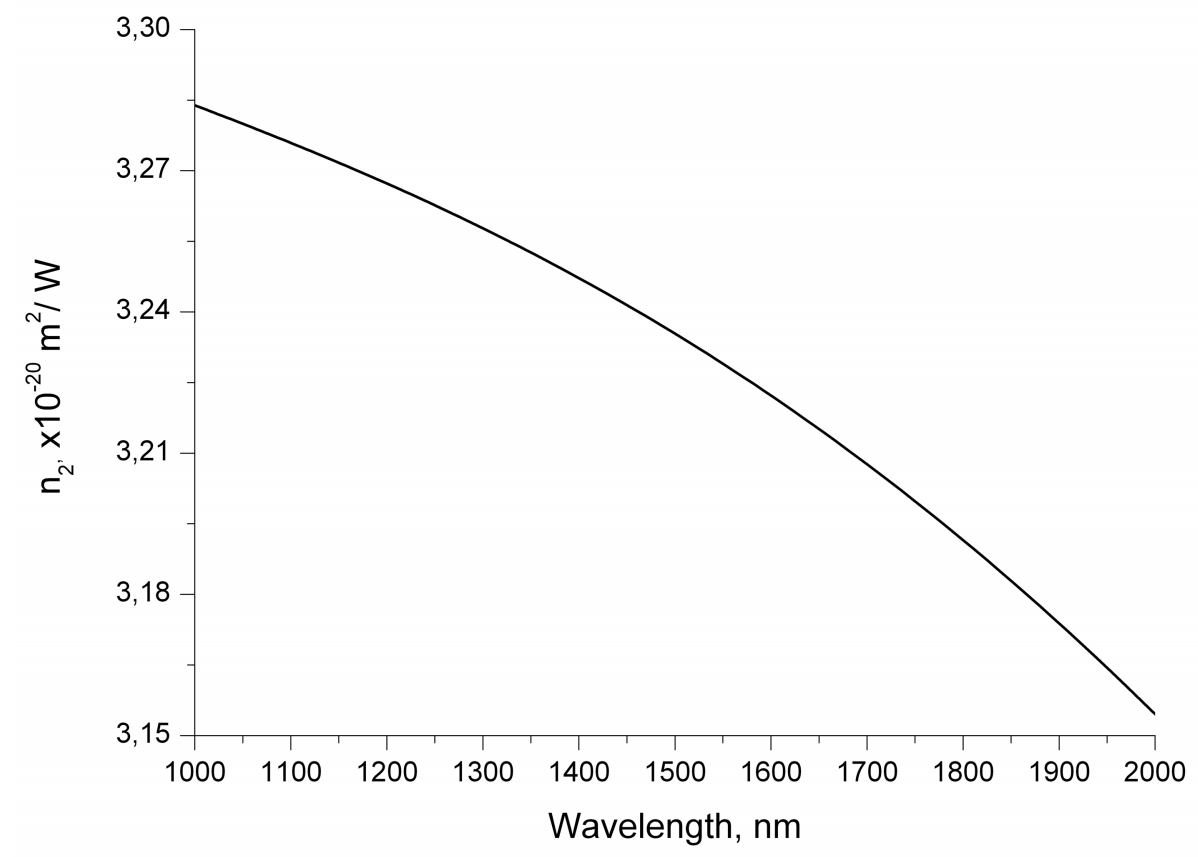

Fig. 9. Effective nonlinear refractive index of the fiber.

Thus, this fiber has a high nonlinear refractive index, in comparison with standard telecommunication fibers, what can be useful for soliton generation and observation of other nonlinear effects [15].

\section{CONCLUSIONS}

In conclusion, we have created a fiber with a high germanium-doped core and with an admixture of bismuth in the silica glass of cladding. Owing to the proximity of the thin bismuth-doped ring to the core, the absorption and luminescence spectra measured upon excitation into the fiber core, have the characteristic bands of active bismuth centers in pure silica glass. The passive optical losses is relatively high $[1,3]$, but they are acceptable for active fibers. The on/off gain of the fiber in a wide spectral range $(1430-1530 \mathrm{~nm})$ was demonstrated. The spectroscopic investigations showed that such type of fiber is promising for the applications in lasers and nonlinear optics.

Authors are deeply grateful to the colleagues, namely, to V. M. Mashinsky, I. A. Bufetov, A. L. Tomashuk and S. L. Semyonov for fruitful discussions.

\section{REFERENCES}

[1] Dianov, E. M., Dvoyrin, V. V., Mashinsky, V. M., Umnikov, A. A., Yashkov, M. V., Guryanov, A. N., “CW bismuth fibre laser", Quantum Electron. 35, 1083-1084 (2005).

[2] Dianov, E. M., Firstov, S. V., Khopin, V. F., Guryanov, A. N., Bufetov, I.A., "Bismuth fibre lasers and amplifiers operating at $1.3 \mu \mathrm{m}$ ", Quantum Electron. 38, 615-617 (2008).

[3] Dvoyrin, V. V., Medvedkov, O. I., Mashinsky, V. M., Umnikov, A. A., Guryanov, A. N., and Dianov, E. M., “Optical amplification in 1430-1495 nm range and laser action in Bi-doped fibers", Optics Express 16 (21), 1697116976 (2008).

[4] Bufetov, I. A., Firstov, S. V., Khopin, V. F., Medvedkov, O. I., Guryanov, A. N., and Dianov, E. M. "Bi-doped fiber lasers and amplifiers for a spectral region of 1300-1470 nm", Opt. Lett. 33, 2227-2229 (2008). 
Dianov, E. M., Firstov, S. V., Khopin, V. F., Medvedkov, O. I., Gur'yanov, A. N., Bufetov, I. A., "Bi-doped fibre lasers operating in the range 1470-1550 nm", Quantum Electron 39 (4), 299-301 (2009).

[6] Neff, M., Romano, V., Luthy, W., "Metal-doped fibres for broadband emission: Fabrication with granulated oxides", Optical Materials 31(2), 247-251 (2008).

[7] Dvoyrin, V.V., Mashinsky, V.M., Bulatov, L.I., Bufetov, I.A., Shubin, A.V., Melkumov, M.A., Kustov, E.F., Dianov, E.M., Umnikov, A.A., Khopin, V.F., Yashkov, M.V., and Guryanov, A.N., "Bismuth-doped-glass optical fibers - a new active medium for lasers and amplifiers, " Opt. Lett. 31, 2966-2968 (2006).

[8] Umnikov, A.A., Guryanov, A.N., Abramov, A.N., Vechkanov, N.N., Firstov, S.V., Mashinsky, V.M., Dvoyrin, V.V., Bulatov, L.I., Dianov, E.M., "Al-free core composition bismuth-doped optical fibre with luminescence band at 1300 nm, ", Optical Communication, ECOC 2008, 1-2 (2008).

[9] Le Noane, G. Hardy, I., and Grosso, P., "Preform manufacturing by FCVD”, IWCS 93 (1993).

[10] Zlenko, A.S., Akhmetshin, U.G., "Features of FCVD method of manufacturing fiber preforms for use in nonlinear optics and laser applications", The third Russian seminar on fiber lasers, pp. 33-35, Ufa, 2009 (in Russian).

[11] Nilsson, J., Minelly, J. D., Paschotta, R., Tropper, A. C., and Hanna, D. C., "Ring-doped cladding-pumped singlemode three-level fiber laser," Opt. Lett. 23, 355-357 (1998).

[12] Nilsson, J., Paschotta, R., Caplen, J. E., and Hanna, D. C., "Yb3+-ring-doped fiber for high-energy pulse amplification," Opt. Lett. 22, 1092-1094 (1997).

[13] Khopin, V. F., Umnikov, A. A., Gur'yanov, A. N., Bubnov, M. M., Senatorov A. K., and Dianov, E. M., "Doping of optical fiber preforms via porous silica layer infiltration with salt solutions", Inorganic Materials 41, 303-307 (2005).

[14] Zlenko, A.S., Akhmetshin, U.G., "Optical fiber doped with active nanofilms into the cladding. Method of preform manufacturing", The third Russian seminar on fiber lasers, pp. 44-46, Ufa, 2009 (in Russian).

[15] Agrawal, G.P., [Nonlinear Fiber Optics], 2nd ed., Academic Press, San Diego (1995).

[16] Akhmetshin, U.G., "The research and development of the single-mode optical fibers with chromatic dispersion varying along the length", Ph.D. Thesis, A.M. Prokhorov General Physics Institute, Moscow, Russian Academy of Sciences, 2003 (in Russian).

[17] Wada, A., Okude, S., Sakai, T., Yamauchi, R., "Geo2 concentration dependence of nonlinear refractive index coefficients of silica-based optical fibers", Electronics and Communications in Japan (Part I: Communications) 79 (11), 12-19 (1996).

[18] Mashinsky, V. M., Neustruev, V. B., Dvoyrin, V. V., Vasiliev, S. A., Medvedkov, O. I., Bufetov, I. A., Shubin, A. V., Dianov, E. M., Guryanov, A. N., Khopin, V. F., Salgansky, M. Yu., "Germania-glass-core silica-glass-cladding modified chemical-vapor deposition optical fibers: optical losses, photorefractivity, and Raman amplification", Opt. Lett. 29 (22), 2596-2598 (2004).

[19] Adair, R., Chase, L. L., and Payne, S. A., "Dispersion of the nonlinear refractive index of optical crystals", Optical Materials 1 (3), 185-194, (1992). 